\title{
DEVELOPMENT OF Ni BASE SUPERALLOY FOR INDUSTRIAL GAS TURBINE
}

\author{
I. Okada ${ }^{1}$, T. Torigoe ${ }^{1}$, K. Takahashi ${ }^{2}$, D. Izutsu ${ }^{2}$ \\ ${ }^{1}$ Mitsubishi Heavy Industries, Ltd. Takasago R\&D Center; 2-1-1 Shinhama Arai-cho Takasago Hyogo 676-8686 Japan \\ ${ }^{2}$ Mitsubishi Heavy Industries, Ltd. Takasago Machinery Works; The same address as above
}

Keywords; Alloy design, Creep rupture strength, Fatigue strength, Blade, Vane

\begin{abstract}
Turbine inlet temperature of the latest MHI's "G" series industrial gas turbine has been approaching $1500^{\circ} \mathrm{C}$. Accompanied by the development of gas turbines with higher firing temperatures, the capability of hot sections materials, such as combustor and turbine parts, must be improved.

In response to this demand, Ni-base superalloys have been developed by MHI's alloy design system. These Ni-base superalloys have been applied to rotating blades and stationary vanes.

Advanced materials have been incorporated in both existing engines to improve the reliability and in the latest engines to realize high efficiency. These advanced materials have shown good results after field operations.
\end{abstract}

\section{INTRODUCTION}

It is known that among numerous factors, industrial Turbine Inlet gas Temperature (TIT, hereafter) has the greatest influence on the thermal efficiency of industrial gas turbine. In other words, the higher TIT means the higher thermal efficiency, as Fig. $1^{(1)}$ shows. In order to achieve higher thermal efficiency, TIT has already reached as high as $1500^{\circ} \mathrm{C}$, which has been realized owing to improvement and development of cooling configuration and materials for hot parts such as turbine blade, vane and combustor.

Among the hot parts, the turbine blades are parts which are used in the severest condition and need the highest reliability. Therefore, in order to cope with rise of TIT, the $\mathrm{Ni}$ base superalloy MGA1400, which is superior in higher temperature strength, combined with corrosion resistance has been developed for application. MGA1400DS has been used for the first and second stage blades of the M501G and up-rated M501F / M701F,

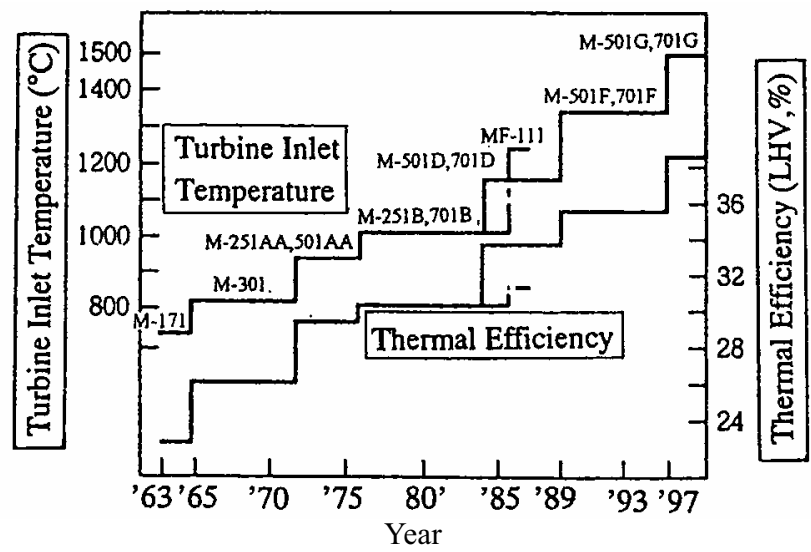

Fig. 1 Evolution of turbine inlet temperature of gas turbine ${ }^{(1)}$ and the first stage blades of the MF-111. Equiaxed MGA1400 has also been used for the latest stage blades of M501G / M701G and so on.

A new Ni-base superalloy MGA2400 for turbine vane application has also been developed. MGA2400 has superior high temperature strength, corrosion resistance and weldability and has been used in the actual gas turbine (M501G / M701G, etc.)

In this paper, MGA1400 and MGA2400 are introduced.

\section{ALLOY DESIGN FOR Ni BASE SUPERALLOY ${ }^{(2)}$}

The high strength at elevated temperature of Ni-base superalloys are obtained by solid solution strengthening and precipitation strengthening. Adding $\mathrm{Cr}$ is very effective for hot corrosion resistance.

In the case of Ni-base superalloys, to obtain properties which is superior in both high temperature strength and corrosion resistance, it is effective to increase the contents of elements such as $\mathrm{Al}$, Ti and etc. forming $\gamma^{\prime}$ phase and $\mathrm{Cr}$ for hot corrosion resistance in the chemical composition. However, the alloy design should be made taking into consideration that the balance of contents of both $\gamma^{\prime}$ phase forming elements and $\mathrm{Cr}$ is important because the excess addition of both elements cause phase unstableness and precipitation of brittle TCP phase such as $\sigma$ phase. Fig. 2 shows the alloy-design flowsheet for $\gamma^{\prime}$ phase precipitate $\mathrm{Ni}$ based super alloy.

Several Ni base alloys have been developed by MHI's alloy design system and have been applied to Mitsubishi Gas Turbines.

\section{TURBINE BLADE ALLOY MGA1400 ${ }^{(2)}$ \\ Properties of Developed Alloy}

The following is the explanation about the conventional cast (CC, hereafter) material's properties of the alloy decided for turbine blades, as the result of the evaluation and investigation of various properties. MGA1400 alloy composition is shown in Table 1 and characterized by being about $14 \mathrm{wt} \%$ in $\mathrm{Cr}$ content, about $11 \mathrm{wt} \%$ in total of $\mathrm{Al}$, Ti and Ta contents, and more than 1 in $\mathrm{Al} / \mathrm{Ti}$ ratio and up to about $56 \%$ in $\gamma$ ' phase volume fraction. In addition, the total content of Mo and $\mathrm{W}$ which are solid solution strengthening elements is increased to about $6 \mathrm{wt} \%$. Moreover, $\mathrm{C}$, etc. were added in order to strengthen the grain boundaries. As shown in Fig.3, the microstructure of CC material conventional cast material (CC, hereafter) after heat treatment (solution treatment and aging) is a typical dendrite structure which is common in cast alloys with a cubic $\gamma^{\prime}$ phase having a size of about $0.6 \mu \mathrm{m}$ and sphere-shaped $\gamma^{\prime}$ phase having a diameter less than $0.1 \mu \mathrm{m}$ that are uniformly and finely precipitated. MGA1400 has excellent properties; tensile strength (at $\mathrm{RT}, 650^{\circ} \mathrm{C}$ ) that is slightly 
Table 1 Nominal composition (wt $\%$ )

\begin{tabular}{|c|c|c|c|c|c|c|c|c|c|c|c|}
\hline & $\mathrm{Ni}$ & $\mathrm{Cr}$ & Co & Mo & $\mathrm{W}$ & $\mathrm{Ta}$ & $\mathrm{Nb}$ & $\mathrm{Ti}$ & $\mathrm{Al}$ & others & arks \\
\hline MGA1400 & Bal. & 14 & 10 & 1.5 & 4.3 & 4.7 & - & 2.7 & 4 & $\mathrm{C}$, etc. & \multirow{2}{*}{$\begin{array}{c}\text { Developed } \\
\text { alloys by MHI }\end{array}$} \\
\hline MGA2400 & Bal. & 19 & 19 & - & 6 & 1.4 & 1 & 3.7 & 1.9 & $C$, etc. & \\
\hline Alloy-A & 10 & 23.5 & Bal. & - & 7 & 3.5 & - & 0.25 & 0.2 & $\mathrm{C}$ & \multirow{3}{*}{$\begin{array}{l}\text { Commercial } \\
\text { alloys for vane } \\
\text { application }\end{array}$} \\
\hline Alloy-B & 10.5 & 25.5 & Bal. & - & 7.5 & - & - & - & - & $C$, etc. & \\
\hline Alloy-C & Bal. & 22.5 & 19 & - & 2 & 1.4 & 1 & 3.7 & 1.9 & $C$, etc. & \\
\hline
\end{tabular}

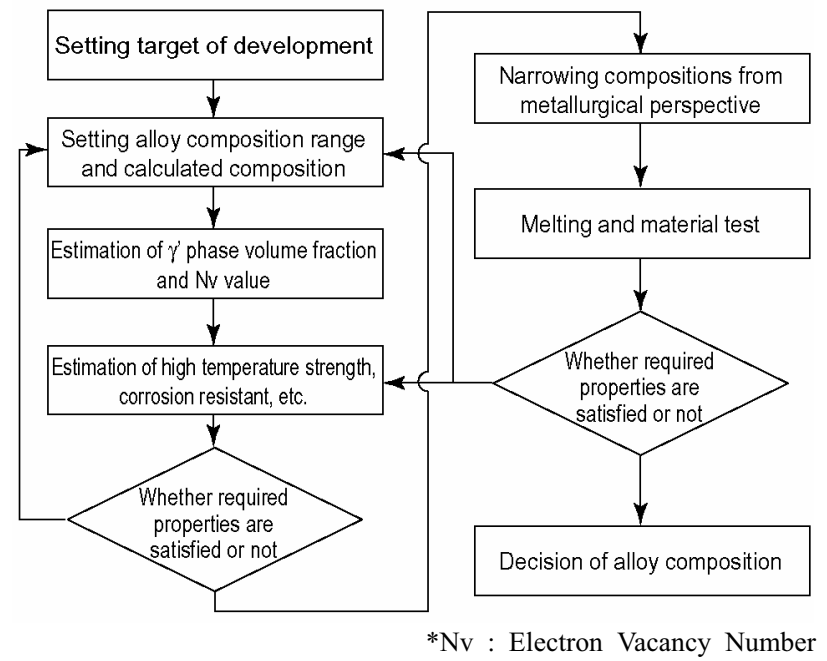

Fig.2 Alloy design concept for $\gamma^{\prime}$ phase precipitate Ni base Superalloy

higher than IN738LC and both elongation and reduction of area of more than 5\%. Fig.4 shows the result of the creep rupture tests, which were conducted at the temperature range from $800^{\circ} \mathrm{C}$ to $1000^{\circ} \mathrm{C}$. MGA 1400 is higher in creep rupture strength and about $30^{\circ} \mathrm{C}$ higher in creep rupture resistant temperature in comparison with IN738LC. Thus the target of the development effort is satisfied.

It also shows excellent properties in fatigue. Corrosion tests using combustion gas from the fuel in which sulfur, sodium and vanadium are added in trace quantity were carried out at $850^{\circ} \mathrm{C}$ and $1000^{\circ} \mathrm{C}$. As a result, MGA1400 showed a few weight change at both temperatures, namely its corrosion resistance was superior to IN738LC as shown in Fig.5. The reason why MGA1400 showed better corrosion resistance in spite of lower $\mathrm{Cr}$ content than IN738LC in which $\mathrm{Cr}$ was $16 \%$ was presumed that its higher $\mathrm{Al}$ content than IN738LC was effective for the higher temperature corrosive environment tested.

\section{Application of Developed Alloy}

As described above, it has been verified that the MGA1400

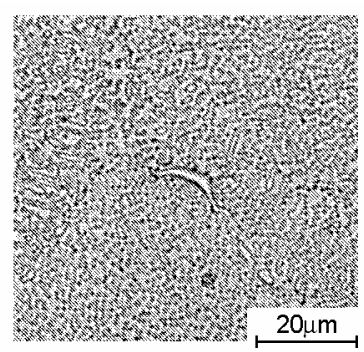

(a) Optical microstructure

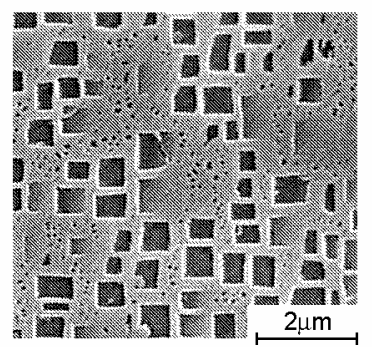

(b) SEM microstructure
Fig.3 Microstructure of MGA1400

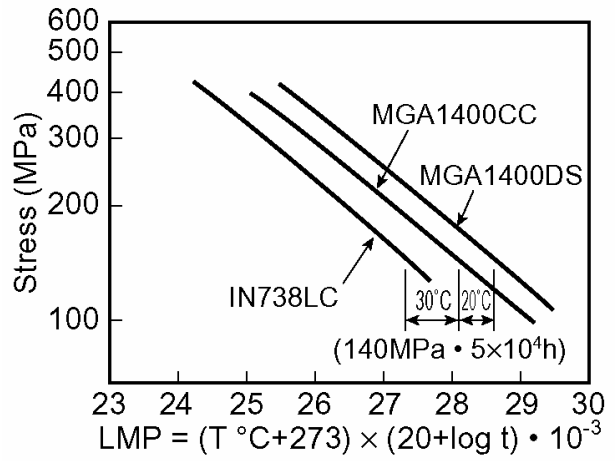

Fig.4 Creep rupture strength of MGA1400 ${ }^{(2)}$

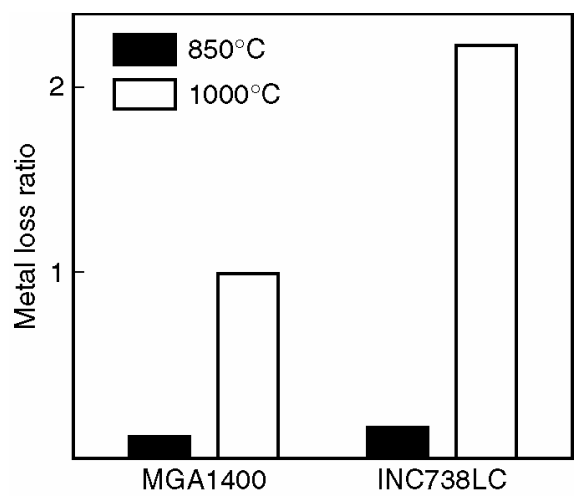

Fig.5 Corrosion resistance of MGA1400 alloy under combustion gas atmosphere

(adding S $0.05 \%$, Na $0.1 \mathrm{ppm}, \mathrm{V} 0.1 \mathrm{ppm}$ to kerosene, Test time 280h)

has excellent properties for gas turbine blade application and is superior to IN738LC in creep rupture strength, fatigue properties, and corrosion resistance. Therefore, CC blades of MGA1400 were experimentally cast to evaluate their properties. Nondestructive inspection, for example, dye penetrate and $\mathrm{X}$ ray tests, were carried out on the experimental blades. As the result shows, casting defects such as casting cracks were not found. Hence for casting, no problem was observed in MGA1400. Taking test pieces from the experimental blades, microstructure, tensile, and creep rupture tests were carried out and these were confirmed to be equivalent to the material properties described previously. Since the excellent properties have also been obtained in the blade materials, these blades have been installed into the actual gas turbines of MF221 and M501DAS types. After two years of use, the turbine blades were cut to be investigated. The outside views of the first stage blade of MF221 gas turbine (operating time; 26,000hrs) and the third stage blade of M501DAS gas turbine (operating time; 25,000hrs) for $1250^{\circ} \mathrm{C}$ class are shown in Fig.6. As a result, it was confirmed that they had maintained their excellent qualities. On the basis of these results, MGA1400 CC has been applied to all stages blades of $\mathrm{M} 701 \mathrm{~F}$ type gas turbine for $1300^{\circ} \mathrm{C}$ class and the third and fourth stage blades of M501G type gas turbine for $1500^{\circ} \mathrm{C}$ class.

Development and Application of Directionally Solidified (DS) Alloy

Further, on the basis of MGA1400 mentioned above, moreover, with investigation on advantage and disadvantage of $\mathrm{Hf}$ 


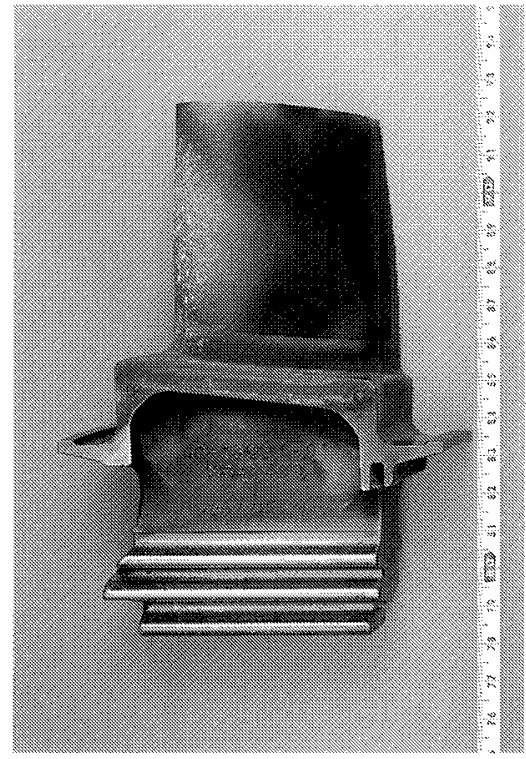

First stage blade MF221 type

(Operating time; 26,000hrs)

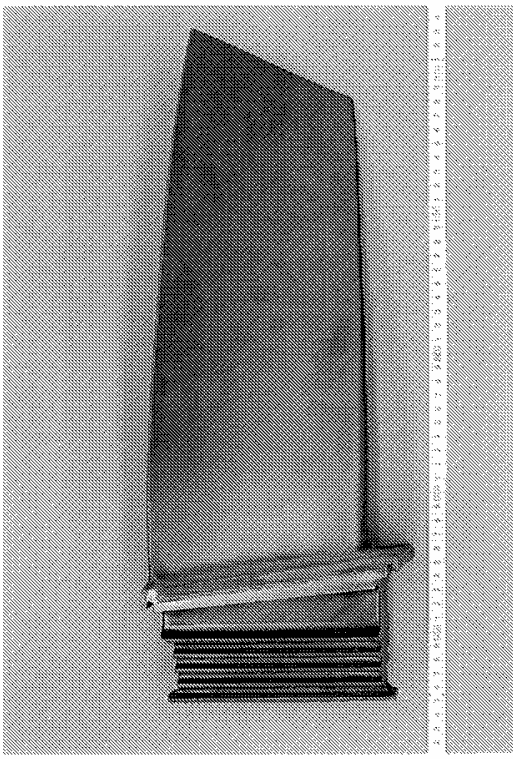

Third stage blade of M501DAS type (Operating time; 25,000hrs)

Fig.6 Outside views of conventional cast blades

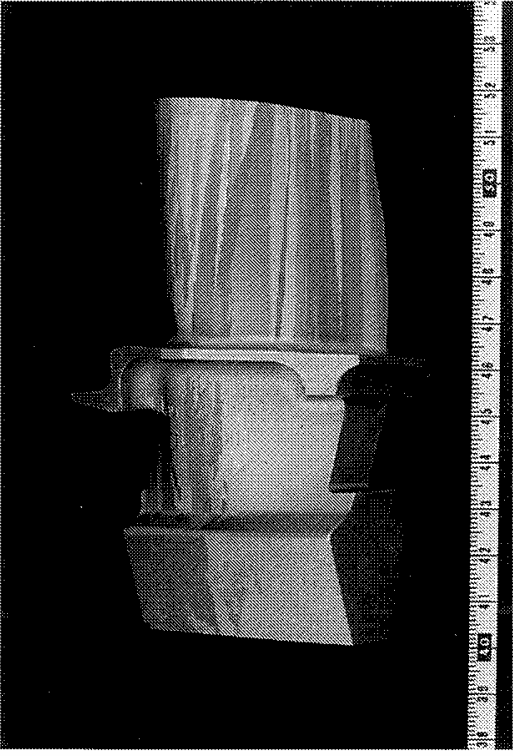

First stage blade of MF111 type

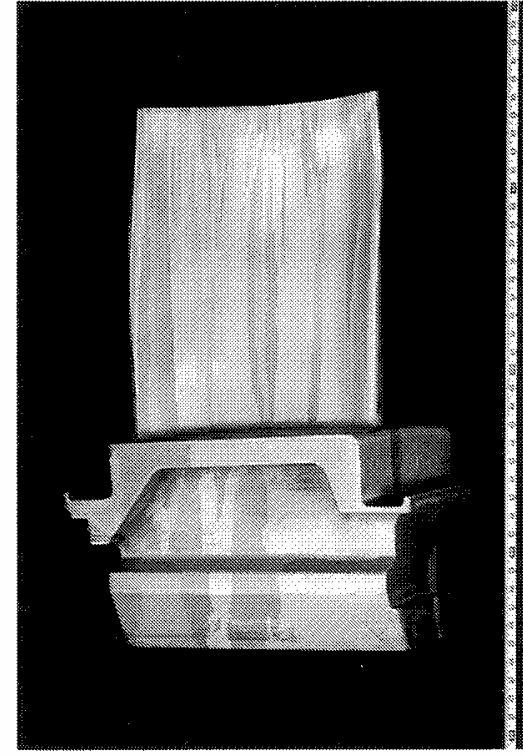

First stage blade of M501G type

Fig.7 Macrostructure and external views of directionally solidified blades

addition and also heat treatment conditions, the DS alloy application was developed. It was confirmed from evaluation of bar and plate materials made of MGA1400DS, that in the columnar grain-growth direction, the creep rupture resistant temperature was about $20^{\circ} \mathrm{C}$ higher than that in MGA1400CC as shown in Fig. 4 and the thermal fatigue life in columnar grains growth direction was improved by about an order of magnitude. The experimentally cast blades had good grain structure as shown in Fig.7 (MF111 type gas turbine of $1250^{\circ} \mathrm{C}$ class and M501G type gas turbine of $1500^{\circ} \mathrm{C}$ class), and the results of nondestructive inspection were also excellent. Eutectic $\gamma^{\prime}$ phase was observed in the inter-dendrite region in the optical micro graph and cubic $\gamma^{\prime}$ phase having a size of about $0.4 \mu \mathrm{m}$ was observed in the SEM micro graph. The difference of $\gamma^{\prime}$ phase morphology between MGA1400DS and MGA1400CC mentioned above was due to different conditions of heat treatment.

For MGA1400DS, solution, stabilizing and aging heat treatments were conducted and the temperature of solution treatment was higher than that of MGA1400CC. The microstructure, tensile and creep rupture properties were taken from these blades and confirmed to be equivalent to those of the bar and plate materials of MGA1400DS. On the basis of these results, MGA1400DS has been applied in M501G and up-rated $\mathrm{M} 501 \mathrm{~F} / \mathrm{M} 701 \mathrm{~F}$ and so on. 


\section{TURBINE VANE ALLOY}

\section{Properties of Developed Alloy}

The microstructure after solution, stabilization and aging heat treatment is shown in Fig.8. The new alloy MGA2400 shows

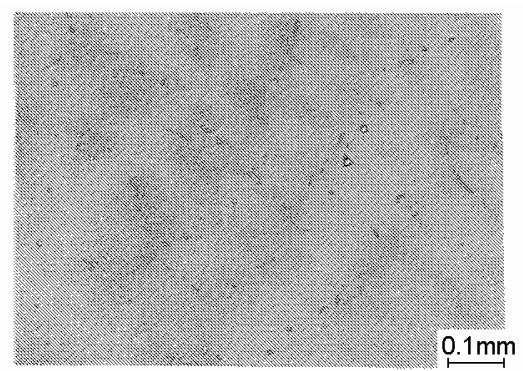

(1) Optical Microstructure

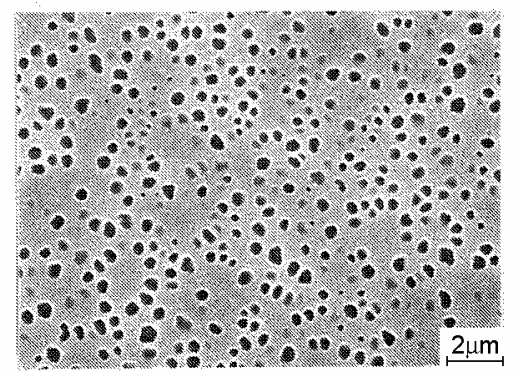

(2) SEM

Fig.8 Microstructure of MGA2400

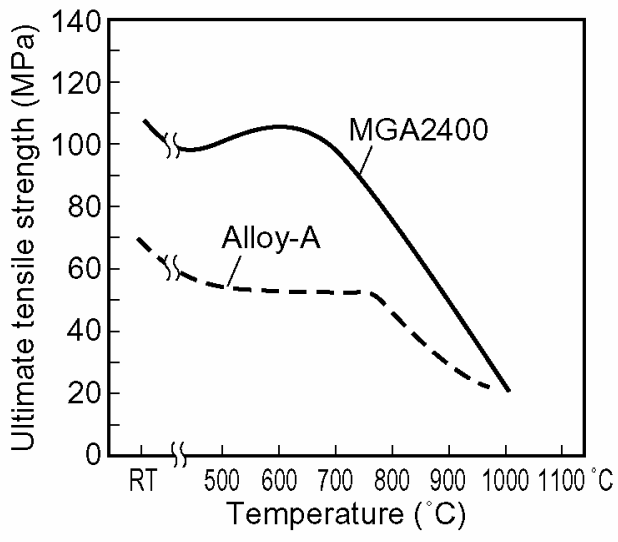

(1) Ultimate tensile strength

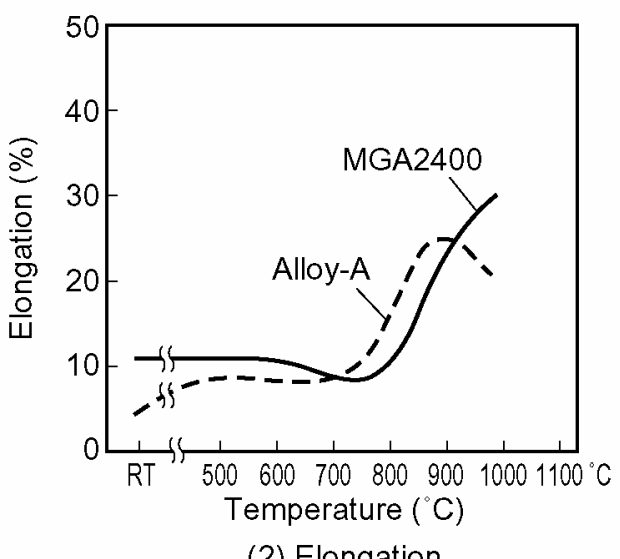

(2) Elongation

Fig.9 Tensile properties of MGA2400 the same normal microstructure as other Ni-base alloys of this type. The observation by scanning electron microscope reveals the uniform and small precipitation of $\gamma^{\prime}$ phase with the size of $0.5 \mu \mathrm{m}$ and finer $\gamma$ ' phase with the size of under $0.1 \mu \mathrm{m}$.

The tensile test was performed at temperatures from room temperature to $1,000^{\circ} \mathrm{C}$. It is verified that $\mathrm{MGA} 2400$ has superior tensile strength to the existing Co based alloy Alloy-A as shown in Fig.9. MGA2400 also shows the equivalent ductility to Alloy-A.

The creep rupture tests were performed at temperatures from $760^{\circ} \mathrm{C}$ to $1,000^{\circ} \mathrm{C}$. The test results were compared with the data of Alloy-A and Alloy-B as shown in Fig.10. It was evident that MGA2400 had superior creep rupture strength to Alloy-A and Alloy-B, as well as it satisfied our development target of creep rupture strength.

Fig. 11 shows the comparison of the data of Alloy-A with the result of thermal fatigue strength test on the new developed alloy. The temperature ranges of the test are $800^{\circ} \mathrm{C}$ to $400^{\circ} \mathrm{C}$ and $900^{\circ} \mathrm{C}$ to $400^{\circ} \mathrm{C}$. Superior thermal fatigue strength is verified for the new alloy.

MGA2400 weldability was evaluated by varestraint test. As stated before, though the alloy has excellent tensile and creep rupture strengths, only slight cracks were observed, which proved its superior strength at elevated temperature and sufficient weldability.

A corrosion resistance test was conducted at a temperature of

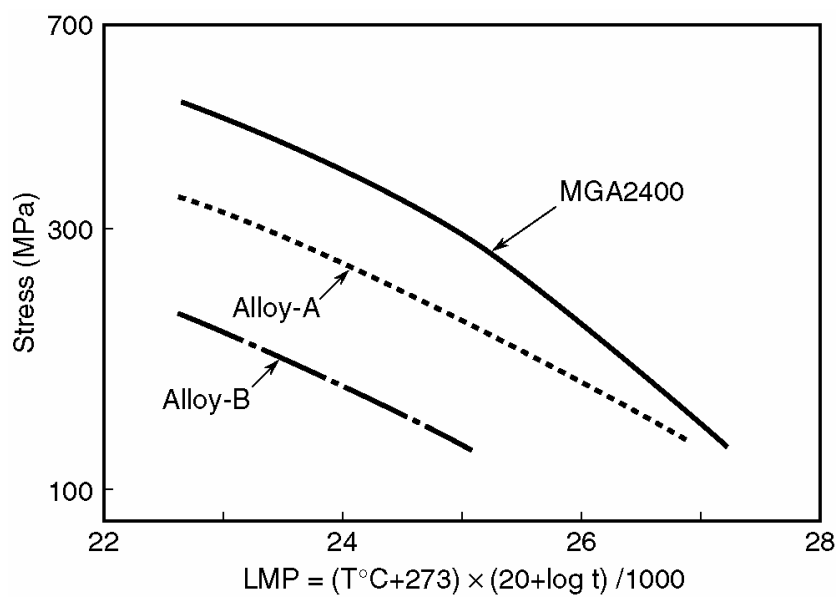

Fig.10 Creep rupture properties of developed alloy

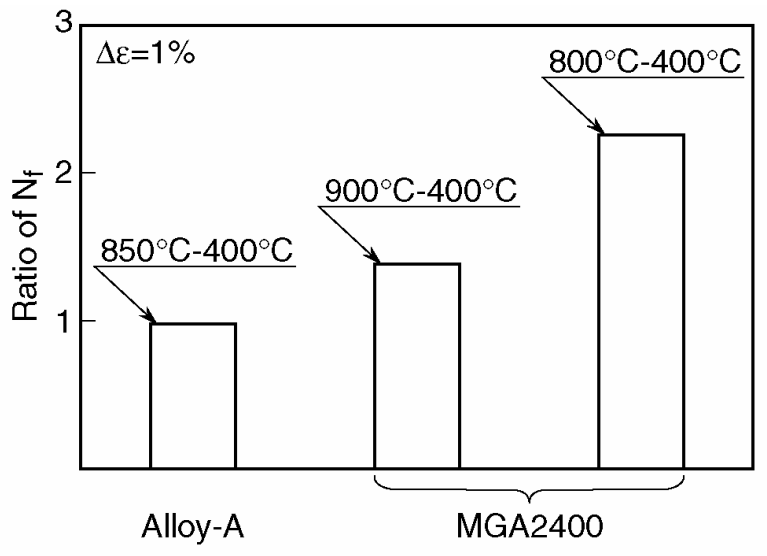

${ }^{*} \mathrm{~N}_{\mathrm{f}}$; Number of cycle to failure

Fig.11 Thermal fatigue properties of MGA2400 


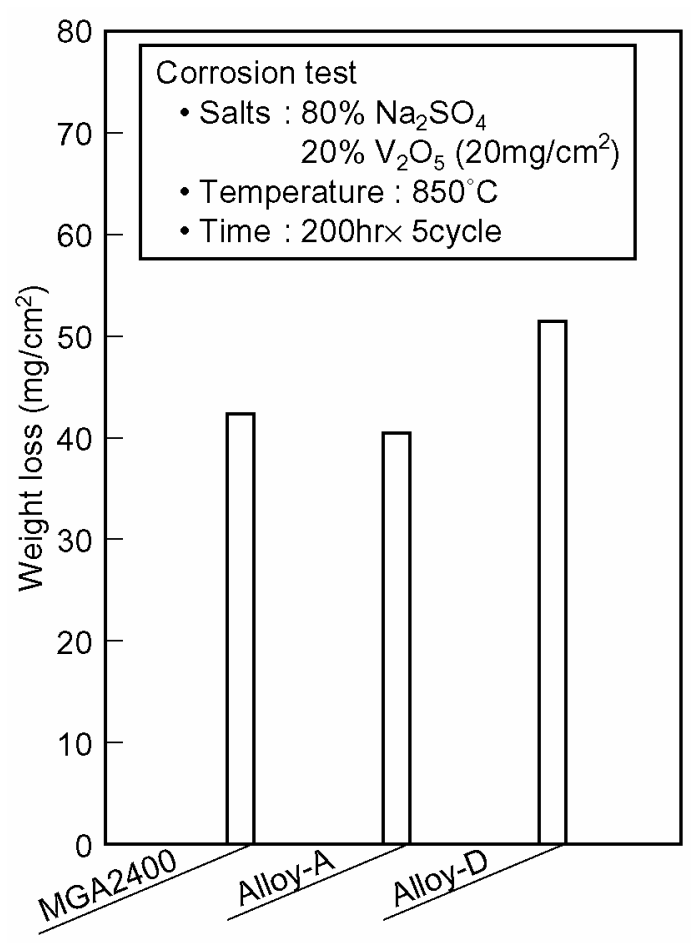

Fig.12 Corrosion test results

$850^{\circ} \mathrm{C}$ in the atmosphere, with a coating molten salt $\left(80 \% \mathrm{Na}_{2} \mathrm{SO}_{4}\right.$ $+20 \% \mathrm{~V}_{2} \mathrm{O}_{5}$ ). As seen from the test result shown in Fig.12, weight loss oft MGA2400 due to corrosion was smaller than Alloy-D, and it was equivalent to Alloy-A.

\section{Application of Developed Alloy}

MGA2400 was verified to have superior high temperature strength such as creep rupture strength and thermal fatigue strength, compared with the existing Co-base alloy. It was also verified that it had sufficient weldability and corrosion resistance. As the next step, its castability was evaluated on conventional cast vanes of MGA2400.

The conventional castings were row 1 vane of MW701D Gas Turbine $\left(1,150^{\circ} \mathrm{C}, 120 \mathrm{MW}\right.$ Class $)$ and large sized row 4 vane of $501 \mathrm{~F}$ Gas Turbine $\left(1,350^{\circ} \mathrm{C}, 150 \mathrm{MW}\right.$ Class $)$ as shown in Fig. 13 . With these vanes, MGA2400 castability was verified through nondestructive inspections (fluorescent penetrate inspection and $\mathrm{X}$-ray radiographic inspection), because no major casting defects, such as cracks were observed.

MGA2400 weldability was evaluated on the actual vane, with the production welding procedure. First, the tested vane was processed with solution heat treatment, then it was welded such as insert welding and overlay welding. Fig.14 shows the view after the welding. No defect is detected by fluorescent penetration inspection.

Fig. 15 shows the microstructure of the welded area, where no crack was observed. It was also verified that MGA2400 had sufficient weldability. As a comparison, a vane was cast with Alloy-D for the same test (weld after solution treatment). In this case, the microstructure reveals a long crack (over $1 \mathrm{~mm}$ ) along a grain boundary (Fig.15). The sufficient weldability of MGA2400 was thus confirmed and it was safe to say that MGA2400 is qualified for practical use in terms of welding.

The normal structure was observed after heat treatment for

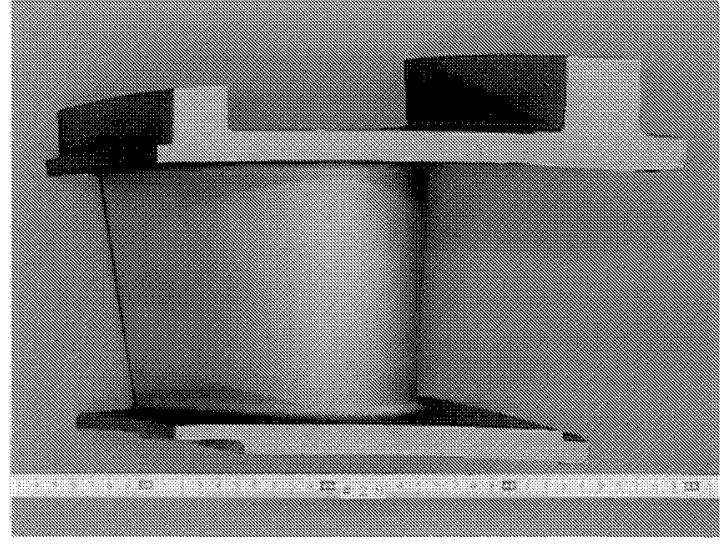

(1) Row 1 vane of M701D

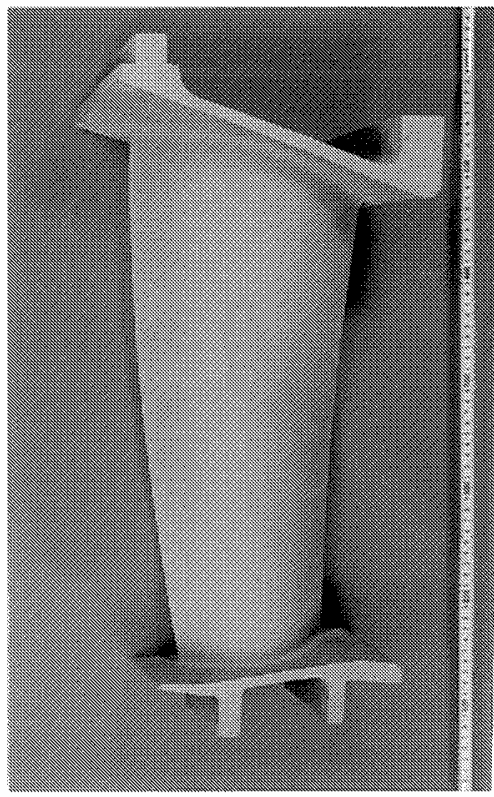

(2) Row 4 vane of M501F

Fig.13 External view of MGA2400 vanes

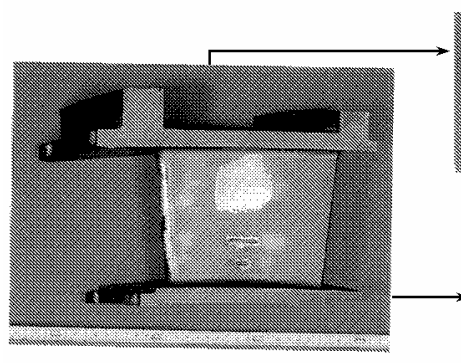

(1) Concave side

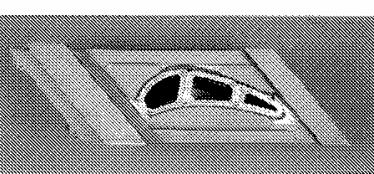

(2) Outer shroud

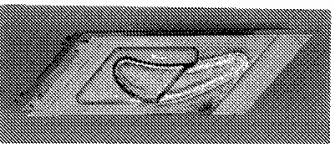

(3) Inner shroud
Fig.14 External view of vane weld test (Row 1 vane of M701D)

the MGA2400 as previously shown in Fig. 8 for the microstructure of separately cast specimen, uniform and minute $\gamma^{\prime}$ phase is precipitated.

Tensile and creep rupture tests were performed on the specimens sampled from actual vanes processed with solution treatment, stabilization and aging treatment. These specimens showed equivalent material characteristics to the separately cast 


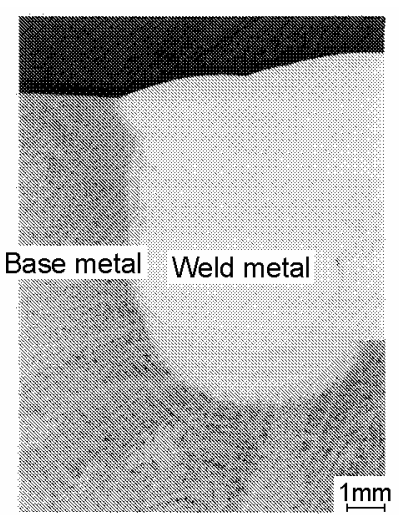

(1) MGA2400

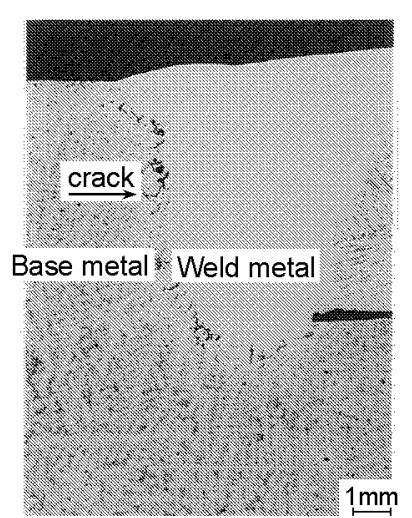

(2) Alloy-D

Fig. 15 Microstructure of welded area

specimens stated before.

In addition to the successful verifications mentioned above on basic material properties of MGA2400 as vane material, its machinability and coating suitability are also confirmed as well as weldability. Based on these, the manufacturing process for the actual vanes with MGA2400 was established. Since January, 1997, MGA2400 vanes has been installed in $1,500^{\circ} \mathrm{C}$ Class M501G Gas Turbine (row 1 to row 4 vanes, conventional cast). The vanes are well operating up to now as expected.

\section{SUMMARY}

MHI have been developed Ni-base superalloys and by MHI's alloy design system and these alloys have been applied to rotating blades (MGA1400CC and MGA1400DS) and stationary vanes (MGA2400).

MGA1400CC has excellent properties in creep rupture, fatigue strength and corrosion resistance. Its creep rupture resistant temperature is improved by $30^{\circ} \mathrm{C}$ in comparison with IN738LC. MGA1400DS is $20^{\circ} \mathrm{C}$ higher in creep resistance and its thermal fatigue life is improved by about an order of magnitude in columnar grains growth direction in comparison with MGA1400CC. Both MGA1400CC and MGA1400DS have good castability.

MGA2400 has superior tensile, creep rupture strength, thermal fatigue strength and weldability. And also, its castability is sufficient to cast the large size vane.

The material development for gas turbine application has been continuously conducted at MHI to meet the most reliable and efficient gas turbine.

\section{ACKNOWLEDGEMENTS}

MHI has developed MGA1400 and MGA2400 with Mitsubishi Materials Co. and Mitsubishi Steel Mfg. Co. respectively. The authors thank these two companies.

\section{REFERENCES}

(1) H. Saeki, et al., Journal of the Gas Turbine Society of Japan, 1996, Vol.24, p.43.

(2) D. Izutsu, I. Okada, H. Kawai et al., International Gas Turbine Congress, November, 1999, p.175.

(3) I. Okada, T. Torigoe, H. Kawai et al., International Gas Turbine Congress, November, 1999, p.1057. 